\title{
Is it worth focusing on product details? How consumers use abstract product information in direct response to product alternatives
}

\author{
WOJCIECH TRZEBIŃSKI, STEFAN DOROSZEWICZ, BEATA MARCINIAK \\ Collegium of Management and Finance \\ SGH Warsaw School of Economics \\ Madalińskiego Street 6/8, 02-513 Warszawa \\ POLAND
}

\begin{abstract}
This paper proposes a model showing how response self-relevance shapes the use of abstract product attributes in the consumer response (i.e., evaluation and choice) to a set of product alternatives perceived directly (i.e., with no accompanying verbal message). The related existing literature scarcely studied the above relationship, focusing instead on consumer response to a verbal message about a single product alternative. The model developed in this paper is examined in multi-stage research, including the main survey on product evaluation and choice, and a preliminary study, using Exploratory Factor Analysis to identify the structure of direct product perception. The results suggest that, for the high self-relevance response (i.e., choosing alternatives for own usage), consumers who process more analytically respond more consistently with the evaluation of abstract attributes. On the other hand, for the low self-relevance response (i.e., mere evaluation of product alternatives), consumers who process more analytically respond more consistently with the evaluation of attributes perceived as important. This paper extends the current views on the relationship between self-relevance and the use of abstract attributes into the domain of the consumer direct response to a set of product alternatives. The findings may support managers in allocating their focus on product attributes between the abstract ones and those perceived as important.
\end{abstract}

Key-Words: - consumer response to a product, product choice, product evaluation, self-relevance, product information abstractness, importance beliefs, consumer information processing

Received: October 18, 2020. Revised: March 4, 2021. Accepted: March 25, 2021. Published: April 8, 2021.

\section{Introduction}

Certain orientations in marketing, such as Marketing 3.0 [1] or transformative services [2], highlight that products and services may deeply influence consumers, making self-relevance (i.e., connection to a consumer's self) a meaningful research area. Recent consumer behavior literature extensively investigates the role of self-relevance (e.g., [3], [4], [5]), also through the lens of the means-end chain (e.g., [6], [7], [8]), relating to the question of how abstract product information (i.e., information that represents several more concrete product attributes [9]) is used by consumers, which is also a recent research focus (e.g., [10], [11], [12]). The existing literature investigates the relationship between self-relevance and the use of abstract information mainly regarding consumers who are planning a purchase and consumers responding to a verbal message on a single product alternative. What especially lacks attention, and is the focus of our research, is how selfrelevance shapes the role of abstract information in the direct consumer response to a set of product alternatives (i.e., when consumers compare them regardless of any verbal message about them). For example, a consumer may test writing pens and perceive their two attributes: ink blurring and one's pleasure of grasping the pen in hand. The first attribute (ink blurring) may provide concrete information, which means low abstractness. Meanwhile, the second attribute (pleasure of grasping it in hand) may contain many aspects, e.g., handiness, easiness of gripping, case inflexibility, which means high abstractness. When will the consumer's pleasure of grasping a pen (vs. ink blurring) be more influential for consumer evaluations and choices? When does abstractness play a larger role in this kind of consumer response? How does it depend on self-relevance? For marketing practice, the above issues highlight which attributes a marketer should focus on when developing and delivering a product. This information may be significant when the consumer response to a product is of high self-relevance, which is likely to happen when companies deeply transform consumers' lives, in line with Marketing 3.0. 
Therefore, in this paper, we propose a novel model of the role of self-relevance that focuses on the direct consumer response to a set of product alternatives, which is scarcely investigated in the existing literature. Compared to most studies in the field, our research is based on the actual product perception identified through Exploratory Factor Analysis (EFA). Our findings suggest that for high selfrelevance direct response to a set of product alternatives, consumers who process product-related information more analytically respond more consistently with their evaluation of abstract product attributes. On the other hand, for a low self-relevance response, consumers processing more analytically respond more consistently with their evaluation of product attributes which they perceive as important. Our results and the method described in this paper may support companies in adapting the production processes to the way consumers tend to respond to products. Using external information flow and factor analysis in process management is of great attention in business; some relevant recent studies can be found in [13] and [14].

\section{Research model}

\subsection{Self-relevance and the use of abstract information}

Self-relevance is the degree to which a certain object (e.g., a product) is connected with consumer goals, motives, and values that are abstract and self-defining for the consumer ([9]). Self-relevance may be also considered related to a brand ([3], [15], [16]), an issue ([5]), or a situation, e.g., brand transgression ([4]). Houston and Walker [9] underline the role of the situation in activating self-related knowledge.

High self-relevance may enhance the use of abstract product-related information, as abstract attributes represent a consumer's personal goals and values more directly [9]. According to Gutman's [17] means-end chain model, consumers group product attributes and then translate them into consequences and consumer values. Thus, abstract (vs. concrete) attributes may be sought as closer to the "end" side of this chain (cf. [6], [7], [8], [11], [18], [19]). The role of self-relevance (or related constructs) in the use of various kinds of product-related information by consumers was studied from few angles. The first is the consumer elaboration on a product category, e.g., at the early stage of planning a purchase, when consumers do not respond to any particular product offer. In the related study on consumer goal mapping, Houston and Walker [9] provided empirical evidence suggesting that self-relevant products may lead consumers to evoke more abstract attributes when they think of a product category. More involved consumers tend to mention more functional consequences of product attributes [20]. Similarly, abstract attributes are demonstrated to be more evoked for "feel"-type product categories [21] and high product risk perception [22] - again, possibly related to self-relevance.

The second angle, from which the role of selfrelevance (or related constructs) in the use of various kinds of product-related information was studied, pertains to how self-relevance may shape the role of abstract information when consumers respond to a verbal message on a single product alternative. In general, the identity goals activation, likely to occur when consumer response is of high relevance, may make consumers use specific attribute information when evaluating a product [23]. Regarding the attribute abstractness, the existing findings provide ambiguous conclusions. For instance, Raimondo et al. [12] demonstrated that for higher brand awareness (possibly related to self-reference), the abstract (vs. concrete) verbal message is more persuasive, which is in line with the means-end approach. Likewise, Liu et al. [24] demonstrated the literal (possibly more concrete vs. figurative) language to be more persuasive in the case of search-type (possibly less self-relevant vs. experience-type) products. Contrarily, earlier research ([25], [26]) showed that for higher consumer product knowledge (also possibly related to self-relevance), a concrete verbal message may be more persuasive. The latter effect may occur because the abstract concepts may be epitomized by concrete information communicated verbally (cf. [27]). Another possible reference may be the Construal Level Theory (CLT), which asserts that people perceive an object in more concrete terms when the psychological distance to it is smaller. Therefore, their attitude towards a psychologically close object is more positive when the message is more concrete ([28], [29], [30]). However, it is hard to determine if a high self-relevant response is connected with larger or smaller psychological distance to a product. Hamilton and Thompson [31] demonstrated that, as regards choosing a product for the own use vs. for somebody else (the first possibly related to a higher self-relevance and a low-distance response), more "concrete" attributes, related to feasibility (vs. desirability), play a larger role in consumer response. But when one operationalizes the low self-relevance response as "mere evaluation", without any specific purpose, the distance to a product may be smaller than in the case of choosing for the own use, as the latter involves additional aspects (such as personal goals, values, and motives) 
that may "obscure" a product, increasing the psychological distance.

\subsection{Consumer response to a set of product alternatives and the use of perceived attribute importance}

In market reality, consumers are typically exposed not to a single product alternative but rather to a set of alternatives. But when it comes to the influence of self-relevance on the consumer use of abstract information in response to a set of product alternatives, the existing research is scarce. This is the first gap our research aims to bridge. What may distinguish the response to a set of product alternatives (from the response to a single alternative) is the role of consumer beliefs on attribute importance. Namely, comparing alternatives may prompt consumers to make trade-offs between attributes, including abstract vs. concrete ones. Then, consumer importance beliefs (i.e., perceptions of an attribute as a source of value within a product category [32]) may play the primary role (e.g., [33]). Attributes perceived as important may be contrasted with the abstract ones as the latter may be considered vaguer (cf. [19]), less important, and attracting less attention ([32], [34]).

Beliefs about the importance of product attributes may be related to perceived norms, e.g., provided by experts or people stating their requests (cf. [35]). In a low self-relevance response to a product, consumers may be less focused on their (personal) values and goals, and in turn, may be more sensitive to normative values related generally to the product category. A similar effect was studied by Tao and $\mathrm{Xu}$ [36]; they demonstrated that consumers less willing to experiment with their appearance (i.e., less focused on themselves) were more dependent on subjective norms when adopting a fashion subscription service. Consequently, a higher focus on the private self may lead to less herd behavior [37]. Simonson and Nowlis [38] found that consumers with a high need for uniqueness made less conventional choices and proposed that such customers' decisions were focused on reasons instead of options. Kwon and Adaval [39] demonstrated that priming consumers with the concept of "going against the flow" leads them to unconventional product choices. Whitley et al. [40] reported that consumers reviewed a more extensive assortment while choosing a product based on hedonic (vs. utilitarian) motivation, which was connected with perceiving their own preferences as more unique. Lotz et al. [41], who studied gift-giving behavior, claim that more normative and formal situations activate less self-relevant goals. The use of normative cues is shown to be diminished when consumers have personal experience with the product [42]. All these results suggest, although indirectly, that response self-relevance may diminish the use of conventions and norms by consumers, and consequently, the role of perceived attribute importance in consumer response.

\subsection{Consumer direct response and the role of analytical processing}

The second gap we intend to overcome in this research is that the existing research about the use of abstract information in consumer response is mostly based on the verbal message about a product (e.g., [12], [25], [26]). However, in market reality, products may be perceived with no accompanying verbal message. Among others, it may happen to simple products like writing pens. When consumers attempt to buy a pen in a shop, they may prefer to watch, grasp, or even test it rather than read its description. For that reason, our research focuses on the direct consumer response (i.e., response based on the direct perception of a product as a stimulus, with no verbal message about it (cf. [31]). In contrast to the verbalbased response, when attributes may be communicated straight and are thus less effortful to use, the use of attribute information in the direct response may be more determined by analytical information processing ([44], [45], [46], [47]). In a more automatic processing mode, people may switch to a similarity-based strategy of object perception instead of the rule-based use of attribute information [45]. Moreover, according to Elaboration Likelihood Model, in the case of the more effortful, central processing route, people rely more on strong arguments [48], which could be related both to more essential (abstract) and perceived-as-important information (cf. [29]). This suggests that analytical processing may enhance the use of both above types of attribute-based product information. Assuming the abovementioned opposition between abstract and perceived-as-important information, one may ask: what determines which of those two types of information will be more enhanced by analytical information processing? We propose the answer could be: the response self-relevance.

The abovementioned research based on the meansend chain model suggests that in the consumer mind, abstract (vs. concrete) product information is more connected to the consumer's personal goals, values, and motives. Therefore, we propose that in the case of a higher response self-relevance, consumers may focus their effort on abstract product information. In other words, self-relevance may increase the degree to which analytical processing enhances the use of abstract product information. It was demonstrated 
[49] that in the case of higher involvement (i.e., the consumer's feeling of personal relevance), consumer elaboration on a product-related message is more focused on product-related thoughts (i.e., the message processing is more integrated with consumer knowledge). As such, in high (vs. low) self-relevance response, consumers may use product information by analyzing the structure of product attributes more deeply. Then, the more abstract attributes (containing a higher number of distinct product features) may be more extensively processed. Therefore, their role in consumer response may be enhanced by analytical processing.

Alba and Marmorstein [50], Ariely [35], and Keller and McGill [51] evidenced that the role of the perceived importance in consumer response may be enhanced by analytical processing, which may lead to effortful consideration of normative beliefs [52] about attribute importance, based on the consistent comparison of the importance of various attributes (cf. [53], [54]). However, as argued above, the response self-relevance may diminish the role of perceived importance as a form of a normative cue. Consequently, the response self-relevance may decrease the degree to which analytical processing enhances the use of information on product attributes that are perceived as important.

This leads to the following expectations (see Fig. 1): H1. In the case of the high self-relevance direct response to a set of product alternatives, the more analytically consumers process information, the more consistent is their response with the alternatives' evaluation in terms of abstract attributes (vs. attributes perceived as important).

H2. In the case of the low self-relevance direct response to a set of product alternatives, the more analytically consumers process information, the more consistent is their response with the alternatives' evaluation in terms of attributes perceived as important (vs. abstract attributes).

In sum, the role of self-relevance in using abstract product-related information by consumers is represented in the existing literature mainly in terms of (1) evoking more abstract attributes when thinking on a product category and (2) response to a verbal message on a single product alternative. Consequently, direct consumer response (i.e., with no accompanying verbal message) to a set of product alternatives remains scarcely investigated in the context of self-relevance and the use of abstract product information. Aiming to overcome this, we have developed a relevant model, proposing that selfrelevance plays a moderating role such that in the high self-relevance response, analytical processing increases the use of abstract-attribute information, while in the low self-relevance response, analytical processing increases the use of information on attributes perceived as important.

Figure 1. Conceptual model

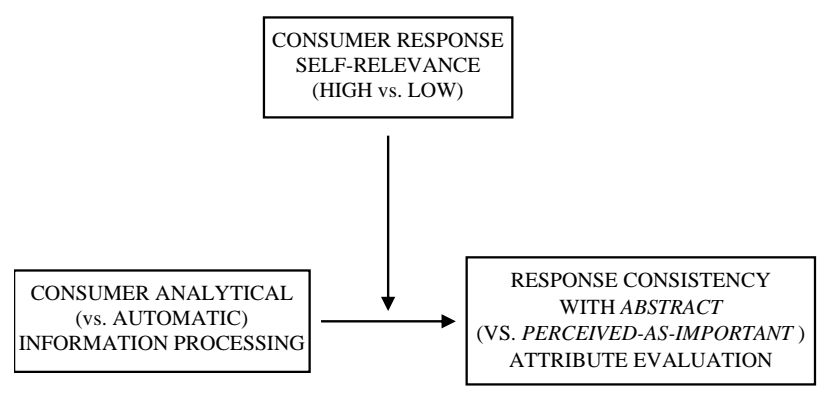

\section{Method}

We present our method in the following order. We start with an overview of our approach. Then, we provide a detailed description of the procedure. Finally, we explain all the measurements we use (i.e., attribute abstractness, attribute perceived importance, degree of analytical information processing, and the consistency between response to product alternatives and their attribute-level evaluations).

\subsection{An overview}

As the product category for our study, we used simple writing blue-ink ballpoint pen with caps, with no ornaments or add-ons. The procedure comprised three stages (1-3), and the results of the preceding stages were used to develop tools for the subsequent stages, so we ensured the correspondence between all three stages by keeping the same studied population, defined as Polish university students. We focused on a homogenous population (in terms of age and education) to avoid possible confounds in the studied relationships. The students participated voluntarily in the fieldwork. All questionnaires were in paper form and group-administered; the anonymity of responses was ensured. To enhance external validity, we used pen alternatives (models) existing in the Polish marketplace as stimuli. In stage 1 (Identification of the product perception structure), the participants were given a pen model and they evaluated it in terms of its detailed features. Based on the set of variables representing those evaluations, we identified pen 
perception dimensions (attributes) using EFA (i.e., the attributes correspond to EFA factors) and indicated the abstractness of each attribute. In stage 2 (Reducing the set of product attributes), the participants indicated the perceived importance of each attribute. Based on attribute abstractness and importance, we defined the reduced set of attributes contrasting in those two properties. Finally, in stage 3 (Assessment of the role of attribute abstractness and perceived importance), the participants were exposed to a set of pen models. They indicated the overall evaluation of each pen model. Using the reduced attribute set, the participants indicated attribute importance and evaluated the models in terms of each attribute based on paired comparisons (cf. [55]); this design aimed to measure the product evaluation better, compared to within-alternative attribute-level measurement ([56]). After that, the participants chose pen models for their own use. The high self-relevance response to the set of pen models was operationalized by extreme responses to those models (i.e., the positive response in the form of choosing the alternatives for the own use (cf. [49]); and the negative response in the form of indicating the worst alternatives in the overall evaluation task). The low self-relevance response was operationalized as indicating the overall evaluation across the entire set of pen models.

Our study is correlational. Although experimental manipulations may better fit identifying causal relationships, we decided to use an individual consumer trait related to analytical processing (i.e., the intuitive and analytical cognitive style, [57]). In all stages of our procedure, we measured the analytical information processing tendency (i.e., cognitive style), and we analyzed data separately for the two cognitive styles, as the product perception may differ between them. Intuitive consumers may be less likely to divide information into components while acquiring knowledge [58], and holistic thinking may lead to more links between product attributes and their consequences [59]. More "cognitively complex" individuals may perceive products through more dimensions due to the more complex structure of their product-related knowledge (cf. [60]). This way, we follow the remarks of Wyer [61], who urges researchers to challenge the implicit assumption that consumers use the information coming from manipulation (or stimuli) instead of their own knowledge. We believe this approach makes the procedure more realistic and supporting external validity.

\subsection{Procedure}

Stage 1 - Identification of the product perception structure. Based on four focus group interviews using projective techniques (sample of 27 participants from our studied population), we developed a list of eighty-four detailed quality features of a pen. Those features (e.g., handiness, easiness of gripping, case inflexibility, being nice to grasp, ink blurring) were mentioned by the participants as considered by them during the purchase and use. To identify the dimensional structure of the product (pen) perception, we ran a quantitative study using a sample of two hundred Polish native-speaker students from our studied population (47.4\% females, $\mathrm{M}_{\mathrm{age}}=23.2, \mathrm{SD}=3.45$ ). The participants evaluated one standardized model of a pen in terms of sixty-four detailed features $(\alpha=.961)$, remaining after scale purification based on a pretest. For each feature, the respondents evaluated the pen using continuous lines; each ended in two metaphors (or similes) describing extreme (negative vs. positive) pen's states regarding the feature, e.g., for the detailed feature "Is the pen nice to grasp?", the negative state was "cactus" (i.e., not being nice to grasp), and the positive one was "friendly hand". Based on detailed feature evaluations as a set of variables, EFA was conducted separately for both cognitive styles (intuitive: $\mathrm{KMO}=.561$, Bartlett's $\mathrm{p}$ $=000$; analytical: $\mathrm{KMO}=.717$, Bartlett's $\mathrm{p}=.000$; VARIMAX rotation with Kaiser's normalization and Kaiser's criterion of an eigenvalue above one). Detailed feature-related variables were assigned to the factors based on factor loadings larger than .400. For each factor, those assigned features were collectively interpreted as a perceived attribute of pens. Sets of detailed features corresponding to those attributes were mutually exclusive. As expected, the dimensional perception structures for each consumer's cognitive style were visibly different, leading to different sets of perceived attributes (16 attributes for the intuitive consumers and 19 attributes for the analytical consumers) and different levels of the abstractness indicator for these attributes.

Stage 2 - Reducing the set of product attributes. To simplify the task for participants, we reduced the number of attributes for attribute-level evaluation measurement. To select the attributes, we complemented the data on attribute abstractness, based on EFA, with the measurement of attribute declared importance. A sample of eighty-nine participants from our studied population $(69.7 \%$ females, $\mathrm{M}_{\mathrm{age}}=24.4, \mathrm{SD}=3.79$ ) ranked pen attributes according to the perceived importance. We determined the cognitive style in the same way as in 
the previous stage. We used a full list of attributes for each cognitive style, reflecting the respective product perception dimensional structure. Then, for each cognitive style, we matched the levels of the attribute abstractness indicator with the levels of the attribute perceived importance and selected the set of four most contrasting attributes (with high abstractness and low importance, or vice versa) that can be differentiated within pen models from the Polish marketplace. Each of these two attribute sets served to represent the product perception for the respective cognitive style. There were two attributes common for both cognitive style sets: "one's pleasure of grasping a pen" and "ink blurring." Apart from that, "elegance" and "general first impression" were the attributes for the intuitive style, while "stylistics" and "writing esthetics" were the ones for the analytical style.

Stage 3 - Assessment of the role of attribute abstractness and perceived importance. A sample of seventy-two participants from our studied population (65.3\% females, $\mathrm{M}_{\mathrm{age}}=22.67, \mathrm{SD}=1.73,38$ intuitive consumers, and 34 analytical consumers) attended seven research sessions (with at least a one-week gap between each). In the beginning, the participants ranked the four attributes from a reduced set according to their importance (separate sets for each cognitive style). Then we exposed the participants to a set of seven models of pens existing in the Polish marketplace. In sessions 2 to 5 , for each attribute from the set for the participant's cognitive style, we measured attribute-level evaluations based on paired comparisons of seven models of pens. Therefore, the participants had to compare 21 pairs of different pen models, indicating the better pen in each pair. Each attribute was assigned to a separate session in random order for each participant. Using the same form of paired comparisons, we measured each model's overall evaluation in session 6 . In the last session, the participants chose two pen models (from the seven models in the stimuli set) for themselves as gifts, which aimed to make the task more realistic, like in [27], [62], and [63]. That gift-giving act was ostensibly not connected with the topic of the study (cf. [64]) to reduce possible demand biases. This was accentuated by conducting that part of the procedure by another researcher, like in [65].

\subsection{Measurements}

Attribute abstractness. We determined the abstractness of each product (pen) attribute identified in EFA in stage 1. For each attribute, we analyzed factor loadings on the corresponding factor. The abstractness of an attribute was indicated by a sum of squared loadings of the variables representing pen evaluations in terms of detailed pen features assigned to the factor. The number of detailed features composing the attribute increases the indicator level. Moreover, this indicator represents a part of the factor variance related to the attribute. Therefore, the indicator denotes the participation of the attribute's perception in the whole product's perception, as measured by product evaluations' variance. This higher participation would indicate a more differentiated product evaluation in terms of the attribute, which may be interpreted as a more complex (abstract) product perception related to the attribute (cf. [66]). This approach is consistent with the definition of product complexity [67] as it includes the number of detailed features, the variance of features evaluation, and the intercorrelation of the features. As mentioned above, for each cognitive style, the sets of detailed features corresponding to the attributes were mutually exclusive. Thus, the attributes embody the same level of the hierarchy. As such, none of the low-abstract attributes is included in any high-abstract attribute. This helps to avoid a situation where some concrete attribute would have a similar meaning to some abstract attribute, which might produce difficulty in comparing the use of attributes of different degrees of abstractness.

Attribute perceived importance. We measured the perceived importance of attributes relying on consciously accessible general beliefs expressed by consumers (declared importance) related to the product category (cf. [32]). We used importance rankings ("Please rank the pen features from the most important one..."), instead of ratings, to enhance the engagement of our participants (cf. [68]).

Analytical information processing. We categorized people - from the most intuitive to the most analytical - using items adapted from Allinson and Hayes's [57] 38 -item measurement scale $(\alpha=.871$, allowing the scores to be aggregated into a single cognitive style index), with a three-point response scale (yes, uncertain and no). Like Mantel and Kardes [46], we indicated intuitive and analytical consumer groups using the median split.

Consistency between response to product alternatives and their attribute-level evaluations. Evaluation of a pen model was measured as the number of other pen models indicated by a participant as worse in the paired comparisons across the set of seven models (therefore, the evaluation ranged from 0 to 6 ). We defined four indicators of the consistency between the consumer response and the attribute-level product evaluation: the indicator of the consistency between high self-relevance response and attribute-level evaluations weighted by attribute abstractness (CAH), the indicator of the consistency 
between high self-relevance response, and attributelevel evaluations weighted by attribute perceived importance $(\mathrm{CPIH})$, the indicator of the consistency between low self-relevance response and attributelevel evaluations weighted by attribute abstractness (CAL), and the indicator of the consistency between low self-relevance response and attribute-level evaluations weighted by attribute perceived importance (CPIL).

The formulas for consistency indicators, presented in detail at the bottom of Table 1 , reflect the abovementioned operationalization of response selfrelevance. The consistency indicators for the high self-relevance response (CAH and $\mathrm{CPIH}$ ) were calculated for each participant as follows. Firstly, we calculated the difference between the averaged attribute-level weighted evaluations of pen models chosen by the participant and the averaged attributelevel weighted evaluations of pen models indicated by the participant as the worst in the paired comparisons. In $\mathrm{CAH}$, the attribute-level evaluations were weighted with attribute abstractness. In CPIH, the attribute-level evaluations were weighted with attribute perceived importance. Then, we calculated the difference between the averaged attribute-level unweighted evaluations of pen models chosen by the participant and the averaged attribute-level unweighted evaluations of pen models indicated by the participant as the worst. This unweighted difference was supposed to represent the use of attribute-level evaluation without considering any attribute weights. Therefore, we subtracted this unweighted difference from the respective weighted difference for each of the high self-relevance consistency indicators.

The consistency indicators for the low self-relevance response (CPIH and CPIL) were calculated for each participant as follows. Firstly, we calculated Pearson's correlation at the set of all seven pen models between the attribute-level weighted evaluations of pen models and those models' overall evaluations. In CAL, the attribute-level evaluations were weighted with attribute abstractness. In CPIL, attribute-level evaluations were weighted with attribute perceived importance. Then, we calculated Pearson's correlation at the set of all seven pen models between the attribute-level unweighted evaluations of pen models and the overall evaluations of those models. This unweighted term was supposed to represent the use of attribute-level evaluation without considering any attribute weights. Therefore, we subtracted this unweighted term from the respective weighted term for each of the low selfrelevance consistency indicators.
Table 1. Consistency between consumer response to product alternatives (pen models) and their attributelevel evaluations - the difference of means between analytical-style consumers $\left(\mathrm{M}_{\mathrm{A}}\right)$ and intuitive-style consumers $\left(\mathrm{M}_{\mathrm{B}}\right)$; unpaired samples t-test. See formulas for the consistency indicators below the table.

\section{HIGH SELF-RELEVANCE RESPONSE CONSISTENCY INDICATORS}

Full sample
\begin{tabular}{|l|c|c|c|c|}
\hline $\begin{array}{l}\text { Consistency indica tor } \\
\text { weighted by ...: }\end{array}$ & t-value & df & $p$ & $\mathbf{M}_{\mathrm{A}}-\mathbf{M}_{\mathbf{I}}$ \\
\hline $\begin{array}{l}\text {..attribute abstractness } \\
\text { (CAH) }\end{array}$ & 4.822 & 70 & .000 & $.545 * * *$ \\
\hline $\begin{array}{l}\text {...attribute perceived } \\
\text { importance(CPIH) }\end{array}$ & 1.457 & 70 & .150 & .156 \\
\hline DIFFERENCE: & 2.380 & 70 & .020 & $.389 *$ \\
\hline
\end{tabular}

Native-speaker subsample

\begin{tabular}{|r|c|c|c|c|}
\hline $\begin{array}{l}\text { Consistency indicator } \\
\text { weighted by...: }\end{array}$ & $\mathbf{t}$-value & $\mathbf{d f}$ & $\boldsymbol{p}$ & $\mathbf{M}_{\mathbf{A}}-\mathbf{M}_{\mathbf{I}}$ \\
\hline $\begin{array}{l}\text {. attribute abstractness } \\
\text { (CAH) }\end{array}$ & 4.148 & 54 & .000 & $.570 * * *$ \\
\hline $\begin{array}{l}\text { attribute perceived } \\
\text { importance (CPIH) }\end{array}$ & 1.827 & 54 & .073 & .234 \\
\hline DIFFERENCE: & -1.713 & 54 & .092 & .335 \\
\hline
\end{tabular}

\section{LOW SELF-RELEVANCE RESPONSE CONSISTENCY INDICATORS}

Full sample
\begin{tabular}{|l|c|c|c|c|}
\hline $\begin{array}{l}\text { Consistency indicator } \\
\text { weighted by .... }\end{array}$ & t-value & $\mathbf{d f}$ & $p$ & $\mathbf{M}_{\mathbf{A}}-\mathbf{M}_{\mathbf{I}}$ \\
\hline $\begin{array}{l}\text {...attribute abstractness } \\
\text { (CAL) }\end{array}$ & .23 & 70 & .819 & .01 \\
\hline $\begin{array}{l}\text {.. attribute perceived } \\
\text { importance (CPIL) }\end{array}$ & 2.589 & 70 & .012 & $.116^{*}$ \\
\hline & -1.914 & 70 & .060 & -.106 \\
\hline
\end{tabular}

Native-speaker subsample

\begin{tabular}{|r|c|c|c|c|}
\hline $\begin{array}{l}\text { Consistency indicator } \\
\text { weighted by...: }\end{array}$ & $\mathbf{t}$-value & $\mathbf{d f}$ & $\boldsymbol{p}$ & $\mathbf{M}_{\mathbf{A}}-\mathbf{M}_{\mathbf{I}}$ \\
\hline $\begin{array}{l}\text {. attribute abstractness } \\
\text { (CAL) }\end{array}$ & .103 & 54 & .918 & .005 \\
\hline $\begin{array}{l}\text {..attribute perceived } \\
\text { importance (CPIL) }\end{array}$ & 3.056 & 54 & .003 & $.163 * *$ \\
\hline DIFFERENCE: & -2.457 & 54 & .017 & $-.158^{*}$ \\
\hline
\end{tabular}

Notes:

$* * * \mathrm{p} \leq .001, * * \mathrm{p} \leq .01, * \mathrm{p} \leq .05$ 
Formulas for consistency indicators:

$$
\begin{aligned}
& \mathrm{CAH}=\mathrm{AB} \_\mathrm{HSR}-\mathrm{UNW} \_ \text {HSR } \\
& \mathrm{CPIH}=\mathrm{PI} \_\mathrm{HSR}-\mathrm{UNW} \_ \text {HSR } \\
& \mathrm{CAL}=\mathrm{AB} \_L S R-\mathrm{UNW} \_ \text {LSR } \\
& \mathrm{CPIL}=\text { PI_LSR }-\mathrm{UNW} \_ \text {LSR }
\end{aligned}
$$

AB_HSR $=\frac{\sum_{\mathrm{j} \in \mathrm{C}}\left(\sum_{\mathrm{k}=1}^{K} \mathrm{ab}_{\mathrm{k}} \mathrm{e}_{\mathrm{k}}^{\mathrm{j}}\right)}{\mathrm{n}}-\frac{\sum_{\mathrm{j} \in \mathrm{R}}\left(\sum_{\mathrm{k}=1}^{K} \mathrm{ab}_{\mathrm{k}} \mathrm{e}_{\mathrm{k}}^{\mathrm{j}}\right)}{\mathrm{m}}$

PI_HSR $=\frac{\sum_{\mathrm{j} \in \mathrm{C}}\left(\sum_{\mathrm{k}=1}^{K} \operatorname{im}_{\mathrm{k}} \mathrm{e}_{\mathrm{k}}^{\mathrm{j}}\right)}{\mathrm{n}}-\frac{\sum_{\mathrm{j} \in \mathrm{R}}\left(\sum_{\mathrm{k}=1}^{\mathrm{K}} \operatorname{im}_{\mathrm{k}} \mathrm{e}_{\mathrm{k}}^{\mathrm{j}}\right)}{\mathrm{m}}$

$\mathrm{UNW}_{-} \mathrm{HSR}=\frac{\sum_{\mathrm{j} \in \mathrm{C}}\left(\sum_{\mathrm{k}=1}^{\mathrm{K}} \mathrm{e}_{\mathrm{k}}^{\mathrm{j}}\right)}{\mathrm{n}}-\frac{\sum_{\mathrm{j} \in \mathrm{R}}\left(\sum_{\mathrm{k}=1}^{\mathrm{K}} \mathrm{e}_{\mathrm{k}}^{\mathrm{j}}\right)}{\mathrm{m}}$

$A B_{-} L S R=\operatorname{corr}\left(\left\{\sum_{\mathrm{k}=1}^{K} \mathrm{ab}_{\mathrm{k}} \mathrm{e}_{\mathrm{k}}^{\mathrm{j}}\right\}_{\mathrm{j} \in \mathrm{S}},\left\{\mathrm{e}^{\mathrm{j}}\right\}_{\mathrm{j} \in \mathrm{S}}\right)$

PI_LSR $=\operatorname{corr}\left(\left\{\sum_{\mathrm{k}=1}^{K} \operatorname{im}_{\mathrm{k}} \mathrm{e}_{\mathrm{k}}^{\mathrm{j}}\right\}_{\mathrm{j} \in \mathrm{S}},\left\{\mathrm{e}^{\mathrm{j}}\right\}_{\mathrm{j} \in \mathrm{S}}\right)$

$U N W_{-} L S R=\operatorname{corr}\left(\left\{\sum_{\mathrm{k}=1}^{\mathrm{K}} \mathrm{e}_{\mathrm{k}}^{\mathrm{j}}\right\}_{\mathrm{j} \in \mathrm{S}},\left\{\mathrm{e}^{\mathrm{j}}\right\}_{\mathrm{j} \in \mathrm{S}}\right)$

\section{Symbols:}

$\mathrm{C}$ - set of two product alternatives (pen models) that were chosen (taken away) by a participant for her or his own usage

$\mathrm{R}$ - set of the two product alternatives (pen models) not chosen by a participant, having the lowest overall evaluation ranking

$\mathrm{S}$ - set of all seven product alternatives (pen models)

$e^{j}{ }_{k}$ - evaluation of product alternative (pen model) $\mathrm{j}$ in terms of attribute $\mathrm{k}$ (measured as the number of product alternatives ranked as less preferred, according to this attribute)

$\mathrm{e}^{\mathrm{j}}$ - overall evaluation product alternative (pen model) $\mathrm{j}$ (measured as the number of product alternatives ranked as less preferred)

$a b_{k}-$ attribute abstractness indicator for attribute $k$, for participant's cognitive style, rescaled to have $\Sigma \mathrm{ab}_{\mathrm{k}}=1$

$\mathrm{im}_{\mathrm{k}}-$ declared importance of attribute $\mathrm{k}$ (based on 1-4 rank scale, where 1 means the lowest importance, and 4 means the highest importance; rescaled to have $\Sigma \mathrm{im}_{\mathrm{k}}=1$ )

$\mathrm{n}$ - number of product alternatives that were chosen (taken away) by a participant for own use

$\mathrm{m}$ - number of the remaining product alternatives (which were not chosen by a participant) having the lowest overall evaluation ranking (0.4 percentile)

corr - Pearson's correlation

$\mathrm{K}$ - number of attributes (equals four)

\section{Results and hypothesis testing}

The research data obtained in stage 3 were analyzed for the full sample (seventy-two participants) and separately for the Polish native-speaker subsample (fifty-six participants) because some relationships were more visible in the latter group, possibly thanks to the reduction of comprehension-related difficulties. All results are shown in Table 1.

First, we compared the high self-relevance consistency indicators by cognitive styles. The indicator of the consistency between consumer response to a set of product alternatives and their attribute-level evaluations weighted by attribute abstractness $(\mathrm{CAH})$ is higher for analytical style consumers (A) compared to intuitive style ones (I), $\mathrm{M}_{\mathrm{A}}-\mathrm{M}_{\mathrm{I}}=.545, \mathrm{t}(70)=4.822, p=.000$. Also, the difference between $\mathrm{CAH}$ and the indicator of the consistency between consumer response and attribute-level evaluations weighted by attribute perceived importance (CPIH) is higher for analytical style consumers compared to intuitive style ones $\left(\mathrm{M}_{\mathrm{A}}\right.$ $\left.-\mathrm{M}_{\mathrm{I}}=.389, \mathrm{t}(70)=2.380, p=.020\right)$. Moreover, there occurs a positive correlation between $\mathrm{CAH}$ and the cognitive style index (higher values of the index indicate more analytical processing), $\mathrm{r}=.327, \mathrm{p}=$ .017 (for native speakers). All this provides support for $\mathrm{H} 1$.

Next, we compared the low self-relevance consistency indicators by cognitive styles. The indicator of the consistency between consumer response to a set of product alternatives and their attribute-level evaluations weighted by attribute perceived importance (CPIL) is higher for analytical style consumers compared to intuitive style ones $\left(\mathrm{M}_{\mathrm{A}}\right.$ $\left.-\mathrm{M}_{\mathrm{I}}=.116, \mathrm{t}(70)=2.589, p=.012\right)$. Also, the difference between CPIL and the indicator of the consistency between consumer response to a set of product alternatives and their attribute-level evaluations weighted by attribute abstractness (CAL) is higher for analytical style consumers compared to intuitive style ones $\left(\mathrm{M}_{\mathrm{A}}-\mathrm{M}_{\mathrm{I}}=.158\right.$, $\mathrm{t}(54)=2.457, p=.017$, among native speakers). All this provides support for $\mathrm{H} 2$.

\section{Discussion}

\subsection{Theoretical implications}

Our findings support the notion of [44], [45], [46], and [47], suggesting that analytical processing may enhance the consumer use of attribute-level product evaluations. While in a low self-relevance response, analytical information processing seems to enhance more the use of attribute perceived as important vs. abstract attributes (in line with [35], [50], and [51]), 
in a high self-relevance response, the situation seems to be opposite: the analytical processing seems to enhance more the use of abstract attributes, which supports the means-end approach, earlier applied to how consumers evoke product information, as when planning a purchase ([9], [20], [21], and [22]). However, while the aforementioned authors focused on how consumers evoke the attributes when planning a purchase, and other authors focused on how consumers respond to a verbal message on a single product alternative ([12], [24], [25], [26]), our study brings evidence for a novel aspect of how consumers form attribute-based preferences when directly responding to a set of product alternatives (i.e., comparing them regardless of any verbal message about them). This way, we demonstrate that the positive effect of self-relevance on abstract information use may also occur in the late-stage purchase process when the abstract information is believed to be less used ([27], [69]). Noteworthy, to investigate the self-relevance effect in direct consumer response, we introduced analytical processing as an additional factor in the model, which is novel compared to the existing research on the topic. Namely, to the best of our knowledge, the existing literature lacks a study that would involve consumer analytical information processing and link response self-relevance with consumer response to abstract product information.

Our findings, suggesting that consumers appear to focus more on perceived importance (considered as general beliefs, possibly reflecting subjective norms related to a product category) in the low (and not high) self-relevance response, provides further support for the ideas of [36], [37], [38], [39], [40], and [41].

Contrary to the dominant view on product information abstractness (e.g., [6], [7], [8], [11]), to better reflect the actual product perception by consumers responding to a product, we analyzed a set of perceived product attributes (in terms of which the product is evaluated) without inclusiveness hierarchy, which is in line with, e.g., [70], and we also applied a novel EFA-based approach to compare the abstractness of non-inclusive attributes.

In sum, our results advance the existing literature on the role of self-relevance in using abstract productrelated information by investigating direct consumer response (i.e., with no accompanying verbal message) to a set of product alternatives.

\subsection{Managerial implications}

Based on the proposed model, companies may develop and deliver their products (focusing on the abstract attributes perceived as less important vs. on the concrete attributes perceived as more important) coherently with the degree to which those products influence consumers' lives and with the stage of the purchase process (both potentially affecting the response self-relevance), and with the purchase situation or consumer characteristics (both potentially affecting the analytical processing). If consumers, in some marketplace setting, directly respond to a set of product alternatives (e.g., by testing them), considering the product's use for themselves (high response self-relevance), then when they process product information more analytically (e.g., being more focused on the response), the use of abstract attributes (vs. attributes perceived as important) should be larger. In this case, a company should offer a product that is superior in attributes of that kind.

Our model may also be applied in companies by using psychographics, e.g., in terms of enduring product involvement (cf. [71]), that may increase response self-relevance, or in terms of cognitive style (cf. [72]). Different levels of analytical (vs. holistic) processing may also result from cultural differences ([59]), which may be meaningful for companies introducing products into various markets (cf. [73]). Alternatively, companies may shape the response self-relevance (e.g., by accentuating a product is to be bought for consumer's own use vs. merely encouraging consumers to evaluate), or may shape the degree of analytical processing (e.g., by reducing the information overload), so that consumers may tend to focus on attributes a given product is superior in. If a company wants to promote a product alternative that is perceived as superior in concrete attributes that are perceived as important, it should encourage consumers to deliberately perform a mere evaluation of various product alternatives (low selfrelevance and high analytical processing), which should lead, according to our model, to the larger role of attributes of that kind.

It is important to note, however, that the above applications should be based on the direct consumer response, i.e., consumers should perceive product alternatives by testing them. By contrast, if product characteristics are verbally communicated, the consumer may not believe in a product alternative's superiority in a particular attribute, or the verbally communicated attributes may be incongruent with the actual product perception structure (e.g., a concrete attribute, like the casing thickness, may epitomize a more abstract one perceived by the consumer, like the pleasure of grasping).

Finally, the conclusions of our study may be beneficial for society, helping consumers to improve the quality of their purchase decisions. Particularly, 
according to our model, when consumers deliberate on products with no apparent consideration to buy (low self-relevance and high analytical processing), they may form their attitudes based on more concrete and normatively important product information. Consequently, the potentially valuable, more abstract information may be underused if the final decision to buy is based on those attitudes. Being aware of this effect may prompt consumers to put more effort into re-evaluating a product.

\section{Conclusions}

Our study extends the existing views on the relationship between self-relevance and the use of abstract attributes into the domain of the direct consumer response to a set of product alternatives and integrates them with analytical information processing and the use of importance beliefs. The results suggest that for the high self-relevance response (i.e., choosing alternatives for own usage), consumers who process more analytically respond more consistently with the evaluation of abstract attributes, while for the low self-relevance response (i.e., mere evaluation of product alternatives), consumers who process more analytically respond more consistently with the evaluation of attributes perceived as important. The findings may support managers in allocating their focus on product attributes between the abstract ones and those perceived as important.

Perhaps the most severe methodological problem we encountered is a differentiation of product perception structure between cognitive styles, which entails the different set of perceived attributes and the different levels of perceived attribute abstractness. Future research related to direct product perception should consider this variety.

Apart from applying our model to other product categories (e.g., related to more hedonic motives) and other consumer groups, our findings can lead to several further research directions. First, mechanisms underlying the role of attribute abstractness (e.g., indepth consideration of the detailed aspects of abstract attributes) appear to be an important area of research. Second, it would be interesting to investigate the relationships proposed here from the perspective of knowledge-based economy phenomena, such as transformative services, which potentially increase consumer response's self-relevance.

\section{References:}

[1] Kotler, P., Kartajaya, H., \& Setiawan, I. (2010)." Marketing 3.0: From products to customers to the human spirit," John Wiley \& Sons.

[2] Anderson, L., A. L. Ostrom, C. Corus, R. P. Fisk, A. S. Gallan, M. Giraldo, M. Mende, M. Mulder, S. W. Rayburn, M. S. Rosenbaum, and K. Shirahada, (2013). "Transformative service research: An agenda for the future," Journal of Business Research 66(8), 1203-1210.

[3] Park, C. W., and MacInnis, D. J. (2018). "Introduction to the special issue: brand relationships, emotions, and the self," Journal of the Association for Consumer Research, 3(2), 123-129.

[4] Trump, R. K. (2014). "Connected consumers' responses to negative brand actions: The roles of transgression selfrelevance and domain," Journal of Business Research, 67(9), 1824-1830.

[5] Einwiller, S., Lis, B., Ruppel, C., \& Sen, S. (2019). "When CSR-based identification backfires: Testing the effects of CSR-related negative publicity," Journal of Business Research, 104, 1-13.

[6] Heinze, J., Thomann, M., \& Fischer, P. (2017). "Ladders to m-commerce resistance: A qualitative means-end approach," Computers in Human Behavior, 73, 362-374.

[7] Lin, C. F., Fu, C. S., and Chen, Y. T. (2019). "Exploring customer perceptions toward different service volumes: An integration of means-end chain and balance theories," Food Quality and Preference, 73, 86-96.

[8] Lin, C. F., and Fu, C. S. (2018). "Evaluating online advertising effect: An approach integrating means-end conceptualization and similarity analysis," Electronic Commerce Research and Applications, 32, 1-12.

[9] Houston, M. B., B. A. Walker (1996). "Self-relevance and purchase goals: mapping a consumer decision," Journal of the Academy of Marketing Science, 24(3), 232-245.

[10] Ding, Y., \& Keh, H. T. (2017). "Consumer reliance on intangible versus tangible attributes in service evaluation: the role of construal level," Journal of the Academy of Marketing Science, 45(6), 848-865.

[11] Pimenta, M. L., \& Piato, É. L. (2016)." Cognitive relationships between automobile attributes and personal values," Asia Pacific Journal of Marketing and Logistics, 28(5), 841-861.

[12] Raimondo, M. A., M. Vernuccio, and G. Micelli. (2019). "The effects of native advertising on consumer responses. Some experimental evidences on the interaction between content type and brand awareness," Mercati \& Competitività, (3), 149-168.

[13] Li, H., Zhao, G. Zhang, Y. C., Ji, Y. (2020), A Modeling Method of Cylindrical Turning Processing Behavior, International Journal of Circuits, Systems and Signal Processing, 14, 1089-1095.

[14] Bakulina, G., V. Fedoskin, V., M. Pikushina, M., V. Kukhar, V., E. Kot, E. (2020), Factor Analysis Models in Enterprise Costs Management, International Journal of Circuits, Systems and Signal Processing 14, 232-240.

[15] Eisingerich, A. B., \& Rubera, G. (2010). "Drivers of brand commitment: A cross-national investigation," Journal of International Marketing, 18(2), 64-79.

[16] Johnson, A. R., Matear, M., \& Thomson, M. (2010). "A coal in the heart: Self-relevance as a post-exit predictor of consumer anti-brand actions," Journal of Consumer Research, 38(1), 108-125.

[17] Gutman, J. (1982). "A means-end chain model based on consumer categorization processes," Journal of Marketing, 46(2), 60-72. 
[18] Graeff, T. R., and J. C. Olson (1994). "Consumer Inference As Part of Product Comprehension", in NA Advances in Consumer Research 21, 201-207.

[19] Snelders, D., and Schoormans, J. P. (2004). "An exploratory study of the relation between concrete and abstract product attributes," Journal of Economic Psychology, 25(6), 803-820.

[20] Mulvey, Michael S., Jerry C. Olson, Richard L. Celsi, and Beth A. Walker (1994). "Exploring the Relationships Between Means-End Knowledge and Involvement", in NA - Advances in Consumer Research 21, 51-57.

[21] Claeys, C., Swinnen, A., \& Abeele, P. V. (1995) "Consumer's means-end chains for "think" and "feel" products," International Journal of Research in Marketing, 12(3), 193-208.

[22] Barrena, R., and M. Sánchez. (2010). "Differences in consumer abstraction levels as a function of risk perception," Journal of Agricultural Economics, 61(1), 34-59.

[23] Xiao, N. (2017). "How identity related goals moderate the role of attributes in product evaluation," Journal of Consumer Behaviour, 16(6), 38-49.

[24] Liu, Z., Lei, S. H., Guo, Y. L., \& Zhou, Z. A. (2020). "The interaction effect of online review language style and product type on consumers' purchase intentions," Palgrave Communications, 6(1), 1-8.

[25] Graeff, T. R. (1997). "Comprehending product attributes and benefits: The role of product knowledge and meansend chain inferences," Psychology \& Marketing, 14(2), 163-183.

[26] Maheswaran, D., and Sternthal, B. (1990). "The effects of knowledge, motivation, and type of message on ad processing and product judgments," Journal of Consumer Research, 17(1), 66-73.

[27] van Ginkel-Bieshaar, M. M. (2012). "The Impact of Abstract versus Concrete Product Communications on Consumer Decision-Making Processes," Erasmus University Amsterdam (No. EPS-2012-256-MKT).

[28] Lee, S. Y., Yoo, C. Y., Kim, D. H., \& Sung, Y. H. (2020). Distance matters: the effects of self-brand connections and construal levels on ad responses. International Journal of Advertising, 1-28.

[29] Trope, Y., \& Liberman, N. (2000). Temporal construal and time-dependent changes in preference. Journal of personality and social psychology, 79(6), 876-889.

[30] Wang, S., \& Lehto, X. (2020). The Interplay of Travelers' Psychological Distance, Language Abstraction, and Message Appeal Type in Social Media Advertising. Journal of Travel Research, 59(8), 14301446.

[31] Hamilton, R. W., and D. V. Thompson. (2007). "Is there a substitute for direct experience? Comparing consumers' preferences after direct and indirect product experiences," Journal of Consumer Research, 34(4), 546-555.

[32] Mackenzie, S. B. (1986). "The role of attention in mediating the effect of advertising on attribute importance," Journal of Consumer Research, 13(2), 174195.

[33] Cohen, J. B., M. Fishbein, and O. T. Ahtola (1972). "The Nature and Uses of Expectancy-Value Models in Consumer Attitude Research," Journal of Marketing Research, IX, 456-460.

[34] Miller, C. H., L. T. Lane, L. M. Deatrick, A. M. Young, and K. A. Potts. (2007). "Psychological reactance and promotional health messages: The effects of controlling language, lexical concreteness, and the restoration of freedom," Human Communication Research, 33(2), 219240.

[35] Ariely, D. (2000). "Controlling the Information Flow: Effects on Consumers' Decision Making and Preferences," Journal of Consumer Research, 27, 233248.

[36] Tao, Q., and Y. Xu (2018)." Consumer Adoption of Fashion Subscription Retailing: The Moderating Effect of Experiment with Appearance," International Textile and Apparel Association (ITAA) Annual Conference Proceedings, 62.

[37] Chen, X., and R. Davison. (2019). "Self-Awareness or Context-Awareness? The Role of Awareness in Herd Behavior," in: "Herd Behavior in Social Commerce," Fortieth International Conference on Information Systems," Münich.

[38] Simonson, I., and Nowlis, S. M. (2000). "The role of explanations and need for uniqueness in consumer decision making: Unconventional choices based on reasons," Journal of Consumer Research, 27(1), 49-68.

[39] Kwon, M., \& Adaval, R. (2017). "Going against the flow: the effects of dynamic sensorimotor experiences on consumer choice," Journal of Consumer Research, 44(6), 1358-1378.

[40] Whitley, S. C., Trudel, R., and Kurt, D. (2018). "The influence of purchase motivation on perceived preference uniqueness and assortment size choice," Journal of Consumer Research, 45(4), 710-724.

[41] Lotz, S. L., Shim, S., \& Gehrt, K. C. (2003). "A study of Japanese consumers' cognitive hierarchies in formal and informal gift- giving situations," Psychology \& Marketing, 20(1), 59-85.

[42] Karahanna, E., Straub, D. W., and Chervany, N. L. (1999). "Information technology adoption across time: a crosssectional comparison of pre-adoption and post-adoption beliefs," MIS Quarterly, 23(2), 183-213.

[43] Hamilton, R. W., and D. V. Thompson. (2007). "Is there a substitute for direct experience? Comparing consumers' preferences after direct and indirect product experiences," Journal of Consumer Research, 34(4), 546-555.

[44] Aarts, H., Verplanken, B., and Knippenberg, A. V. (1997). "Habit and information use in travel mode choices," Acta Psychologica, 96, 1-14.

[45] Hoffmann, J. A., von Helversen, B., and Rieskamp, J. (2013). "Deliberation's blindsight: How cognitive load can improve judgments," Psychological Science, 24(6), 869-879.

[46] Mantel, S. P., and Kardes, F. R. (1999). "The role of direction of comparison, attribute-based processing, and attitude-based processing in consumer preference," Journal of Consumer Research, 25(4), 335352.

[47] Scheibehenne, B., B. von Helversen, J. Rieskamp (2015). "Different strategies for evaluating consumer products: Attribute-and exemplar-based approaches compared," Journal of Economic Psychology, 46, 39-50.

[48] Petty, R. E., \& Cacioppo, J. T. (1984). The effects of involvement on responses to argument quantity and quality: Central and peripheral routes to persuasion. Journal of personality and social psychology, 46(1), 69-81.

[49] Celsi, R. L., and Olson, J. C. (1988). "The role of involvement in attention and comprehension processes," Journal of Consumer Research, 15(2), 210224. 
[50] Alba, J. W., H. Marmorstein (1987). "The Effects of Frequency Knowledge on Consumer Decision Making," Journal of Consumer Research, 14(1), 14-25.

[51] Keller, P. A., and McGill, A. L. (1994). "Differences in the relative influence of product attributes under alternative processing conditions: Attribute importance versus attribute ease of imagability," Journal of Consumer Psychology, 3(1), 29-49.

[52] Smith, E. R., and J. DeCoster (2000). "Dual-Process Models in Social and Cognitive Psychology: Conceptual Integration and Links to Underlying Memory Systems," Personality and Social Psychology Review, 4(2), 108131.

[53] Bettman, J. R., Mary Frances Luce, and John W. Payne (2008). "Consumer Decision Making: A Choice Goals Approach," in Haugtvedt, C. P., Herr, P.M. Kardes, F. R. (ed.), Handbook of consumer psychology, Taylor \& Francis, New York, London, 588-609.

[54] Park, C. W., and D. C. Smith (1989). "Product-level choice: a top-down or bottom-up process?," Journal of Consumer Research, 16(3), 289-299.

[55] Meissner, M., and R. Decker (2009). "An empirical comparison of $\mathrm{CBC}$ and AHP for measuring consumer preferences," Proceedings of the International Symposium on the Analytic Hierarchy Process 2009.

[56] Vera-Martinez, J., and Ornelas, S. (2019). "Comparisonbased perceived attribute performance as a better antecedent of satisfaction, value and loyalty," Asia Pacific Journal of Marketing and Logistics, 31(15), 1252-1268.

[57] Allinson C. W., J. Hayes (1996). "The Cognitive Style Index: A Measure of Intuition-Analysis for Organizational Research," Journal of Management Studies, 33(1), 119-135.

[58] Riding, Richard J., Eugene Sadler- Smith (1997). "Cognitive style and learning strategies: Some implications for training design," International Journal of Training and Development, 1(3), 199-208.

[59] Choi, B. (2019). "The relation between culture and psychological processes of consumers," in: A. Bonomo, V. Corona-Cabrera, E. Norman-Acevedo, J. C. SosaVarela (eds.), "Customer Cultura Studies", Institución Universitaria Politécnico Grancolombiano, Bogotá, 95109.

[60] Walker, B., R. Celsi, and J. Olson (1987). "Exploring the Structural Characteristics of Consumers' Knowledge", in NA - Advances in Consumer Research 14, 17-21.

[61] Wyer, R. S. (2008). "The role of knowledge accessibility in cognition and behaviour," in Haugtvedt, C. P., Herr, P.M. Kardes, F. R. (ed.), "Handbook of Consumer Psychology," Taylor and Francis, New York, London, 4, 31-76.

[62] Fazio, Russel H., Martha C. Powell, Carol J. Williams (1989). "The Role of Attitude Accessibility in the Attitude-to-Behavior Process," Journal of Consumer Research, 16, 280-288.

[63] Wan, E. W., R. P. Chen, and L. Jin. (2017). "Judging a book by its cover? The effect of anthropomorphism on product attribute processing and consumer preference," Journal of Consumer Research, 43(6), 1008-1030.

[64] Xu, A. J., and R. S. Wyer Jr. (2007). "The effect of mindsets on consumer decision strategies. Journal of Consumer Research," 34(4), 556-566.

[65] Bettman, J. R., Sujan, M. (1987). "Effects of framing on evaluation of comparable and noncomparable alternatives by expert and novice consumers," Journal of Consumer Research, 14(2), 141-154.
[66] Doroszewicz, S. (2014). "The Method of Classification of Consumer Attitude Accessibility in Relation to Inherent Product Features," Polish Journal of Natural Sciences, 29(2), 211-223.

[67] Xiao, B., and Benbasat, I. (2007). "E-commerce product recommendation agents: use, characteristics, and impact," MIS Quarterly, 31(1), 137-209.

[68] Abalo, J., J. Varela, and V. Manzano. (2007). "Importance values for Importance-Performance Analysis: A formula for spreading out values derived from preference rankings," Journal of Business Research, 60(2), 115-121.

[69] Lee, L., and D. Ariely. (2006). "Shopping goals, goal concreteness, and conditional promotions," Journal of Consumer Research, 33(1), 60-70.

[70] Parasuraman, A., Zeithaml, V. A., and Malhotra, A. (2005). " E-SQUAL. A Multi-item Scale to Assess Electronic Service Quality," Journal of Service Research, 7, X, 1-21.

[71] Park, M., Yang, X., Lee, B., Jang, H. C., and Stokowski, P. A. (2002). "Segmenting casino gamblers by involvement profiles: A Colorado example," Tourism Management, 23(1), 55-65.

[72] Gaston-Breton, C., and L. C. Duque. (2015). "Utilitarian and hedonic promotional appeals of 99-ending prices: The influence of decision-making style," European Journal of Marketing, 49(1/2), 212-237.

[73] Horska, E., Ubreziova, I., \& Kekale, T. (2007). "Product adaptation in processes of internationalization: Case of the Slovak food-processing companies," Baltic Journal of Management, 2(3), 319-333.

\section{Contribution of individual authors to the creation of a scientific article (ghostwriting policy)}

All the authors participated in model development. Wojciech Trzebiński and Beata Marciniak carried out data collection, and Wojciech Trzebiński carried out data analysis and was responsible for preparing the manuscript.

\section{Sources of funding for research presented in a scientific article or scientific article itself}

This research was supported by the grant of SGH Warsaw School of Economics, grant no. KZIF/56/17.

\section{Creative Commons Attribution}

\section{License 4.0 (Attribution 4.0 International , CC BY 4.0)}

This article is published under the terms of the Creative Commons Attribution License 4.0 https://creativecommons.org/licenses/by/4.0/deed.en US 